Jennifer L. Woods*, Devon J. Hensel and J. Dennis Fortenberry

\title{
More like him, me, or us: the impact of trait similarity on adolescent women's sexual risk behaviors in relationships
}

DOI 10.1515/ijamh-2016-0078

Received July 16, 2016; accepted August 4, 2016; previously published online August 17, 2016

Abstract: Ideal partner traits and how they relate to a young woman's current partner and relationship is a knowledge gap in the literature. The objectives of this study were 1) to assess any differences in interpersonal characteristics between a young woman or her partner and relationship and 2) to examine the impact of this difference on sexual monogamy, condom use and frequency of vaginal sex. Study participants ( $\mathrm{n}=387,14-17$ years at enrollment, 90\% African American) were recruited from three primary care adolescent health clinics serving areas with high rates of unintended pregnancy and sexually transmitted infection (STI); data were drawn from a longitudinal cohort study of sexual relationships and behaviors among young women. Nineteen interpersonal characteristics, including physical, financial, communication and personal characteristic variables, were found to have varying influences on relationships and sexual behaviors with 'like him' and 'like us' as referents. Monogamy increased as a male partner wanted to get somewhere in life [OR 5.41, $(1.25,23.52, \mathrm{p}<0.05)]$, was intelligent [OR 3.42, $(1.09,10.76, \mathrm{p}<0.05)]$ and had money [OR 1.55, $(0.272,0.595, \mathrm{p}<0.001)]$ in a partnership; monogamy similarly increased when a partner wanted to get somewhere in life [OR 6.77, $(1.51,30.36, \mathrm{p}<0.01)$ ], was intelligent [OR 4.02, $(1.23,13.23, \mathrm{p}<0.05)]$, and had money [OR $2.41,(1.51,3.84, \mathrm{p}<0.001)]$ compared to the young woman. The likelihood of using a condom at last sex increased when the male partner had a nice body [OR 1.42, (1.02, $1.99, \mathrm{p}<0.05)$ ], was popular [OR 1.60, $(1.12,2.29, \mathrm{p}<0.01)$ ], cared for others [OR 3.43, $(1.32,8.98, \mathrm{p}<0.01)$ ], was good at sports [OR 1.35, $(1.06,1.73, \mathrm{p}<0.05)]$ and expressed his feelings [OR 2.03, $(1.14,3.60, \mathrm{p}<0.01)]$. The condom use

\footnotetext{
*Corresponding author: Jennifer L. Woods, Section of Adolescent Medicine, Children's Hospital Colorado,13123 East Colfax Avenue, B025, Aurora, CO 80045, USA, Phone: +(720)777-8054,

Fax:+(720)777-7339, E-mail: jennifer.woods@childrenscolorado.org Devon J. Hensel and J. Dennis Fortenberry: Section of Adolescent Medicine, Indiana University School of Medicine, 410 W. 10th Street, Room 1001, Indianapolis, IN 46202, USA
}

ratio increased when the male partner was able to take care of himself [OR $0.076,(0.017,0.136, \mathrm{p}<0.01)]$, was cute [OR 0.190, $(0.082,0.30, \mathrm{p}<0.001)]$, and had a nice body [OR 0.044, $(0.001,0.09, \mathrm{p}<0.05)]$ in a dyad; the condom use ratio also increased when a male partner could take care of himself [OR 0.091, $(0.014,0.168, \mathrm{p}<0.05)]$, was cute [OR 0.194, $(0.077,0.311, \mathrm{p}<0.001)]$ compared to the young woman. Coital frequency increased when the male partner was described as being able to take care of himself [OR 3.33, $(0.138,6.52, \mathrm{p}<0.05)]$. Such influences are important in discussions with young women regarding personal and partner choices in sexual health as partners, behaviors and motivations for choice frequently change.

Keywords: adolescents; relationship; sexuality.

\section{Introduction}

Adolescent women are disproportionately impacted by sexually transmitted infections (STI) in the United States (1). Existing literature emphasizes how characteristics of a romantic/sexual relationship influence a young woman's participation in STI-associated sexual behaviors (2), particularly in terms of whether a partner meets her ideal expectations for a relationship and the extent to which a woman and her partner are similar on those ideals (3, 4). For example, a partner falling below expectations on emotional support, fidelity or social/economic status is associated with multiple sex partners and sexual partner concurrency $(5,6)$. Emotional and social similarity also predicts better relationship functioning with less jealousy, physical aggression and higher relationship quality (7).

Ideal partner characteristics have been previously studied for adult relationships. Physical attractiveness in short- and long-term partnerships is important for men $(8,9)$ while women value attractiveness in short-term relationships and social status (i.e. salary) for long-term relationships $(10,11)$. Actual sexual partners fulfill ideal characteristics to differing levels due to factors such as availability and fertility potential. In contrast, few studies have examined adolescent partnerships and ideal partner 
characteristics. These studies have emphasized that attractiveness and social status are also key components of relationships for teens in addition to a need for emotional support $(5,12)$.

An important gap in the current body of research is a young woman's personal ordering of an ideal trait and evaluation of her partner and relationship for the same trait. Discordance in these traits could suggest relationships where attention to emergence or continuation of sexual risk behaviors is warranted. Accordingly, the objectives of this study were to assess any differences in interpersonal characteristics between a young woman or her partner and relationship, and to examine the impact of this difference on sexual monogamy, condom use and frequency of vaginal sex.

\section{Methods}

\section{Participants and study design}

Data were drawn from a longitudinal cohort study (1999-2009) of sexual relationships and sexual behaviors among young women $(n=387$, 14-17 years at enrollment, 90\% African American). Participants were from three primary care adolescent health clinics serving lower- and middle-income families residing in areas with high rates of unintended pregnancy and STIs. Potential participants were eligible if they were between the ages of 14 and 17 years, spoke English, and were not pregnant at study enrollment. For the larger study, participants who became pregnant continued in the project; however, analyses in the present study were limited to those adolescents who were not pregnant.

Data were obtained from enrollment and quarterly face-to-face interviews which assessed sexual relationships and behaviors including: number of sexual partners, coital events, utilization of contraception methods, attitudes about current sexual relationships and behaviors. Young women provided quarterly partner-specific (up to five) information on interpersonal and sexual behavior content in their relationships. Interviews lasted between 35 and $40 \mathrm{~min}$, and subjects were compensated $\$ 20.00$ for each completed interview. More detailed descriptions of these methods have been described previously (13). Adolescent informed consent and permission from parent or legal guardian were obtained; research was approved by the IRB of Indiana University/Purdue University at Indianapolis - Clarian.

\section{Measures}

Sexual risk behavior outcome variables: Outcome variables of the study were: "current relationship monogamy" (no/yes), “condom use at last sex" (no/yes), "coital frequency", and "ratio of condom use during vaginal sex". For this study, our analysis is limited to penilevaginal intercourse although the larger study also evaluated oral sex, anal sex and genital touching.

Interpersonal characteristic predictor variables: Nineteen interpersonal characteristics were assessed in the interview utilizing the following descriptions: more like you than your partner ("like me"), more like your partner ("like him"), and about the same for both of you ("like us"). The interpersonal characteristics acted as predictor variables of sexual behaviors within the young women's sexual partnerships. The characteristics included descriptors of physical appearance, financial stability, communication and personal descriptors:

- Physical variables:

Nice body, cute face, dresses well, smells nice

- Financial variables:

Nice car, money

- Communication variables:

Easy to talk to, able to express feelings, cares for others

- Personal characteristics variables:

Good sense of humor, able to take care of self, wants to get somewhere in life, intelligent, comes from a good family, good at sports, likes to have fun, likes kids, willing to take chances, comes from a good family, popular with other people.

\section{Procedure}

Generalized estimating equation (GEE) ordinal logistic or linear regression assessed the association between interpersonal characteristics and sexual risk behaviors, adjusting estimates for repeated data from the same participant. Each interpersonal characteristic was evaluated one at a time using "like him" as the referent category, resulting in four models (SPSS, 22.0). All models additionally controlled for young women's age, race/ethnicity and other relationship traits such as relationship quality and commitment known to influence sexual risk behavior (2).

\section{Results}

\section{Current relationship monogamy}

\section{Like Him v. Like Us}

Monogamy was significantly more likely for a partnership when wanting to get somewhere in life [OR 5.41, $(1.25,23.52, \mathrm{p}<0.05)$ ], being intelligent [OR 3.42, (1.09, 10.76, $\mathrm{p}<0.05)$ ], and having money [OR 1.55, (0.272, 0.595, $\mathrm{p}<0.001)$ ] were more like the male partner compared to the couple, or dyad (Table 1).

In contrast, monogamy significantly decreased when being popular with other people [OR 0.402, (0.272, 0.595, $\mathrm{p}<0.01)$ ] was more like the young man than the dyad.

\section{Like Him v. Like Me}

Current relationship monogamy was significantly more likely when wanting to get somewhere in life 


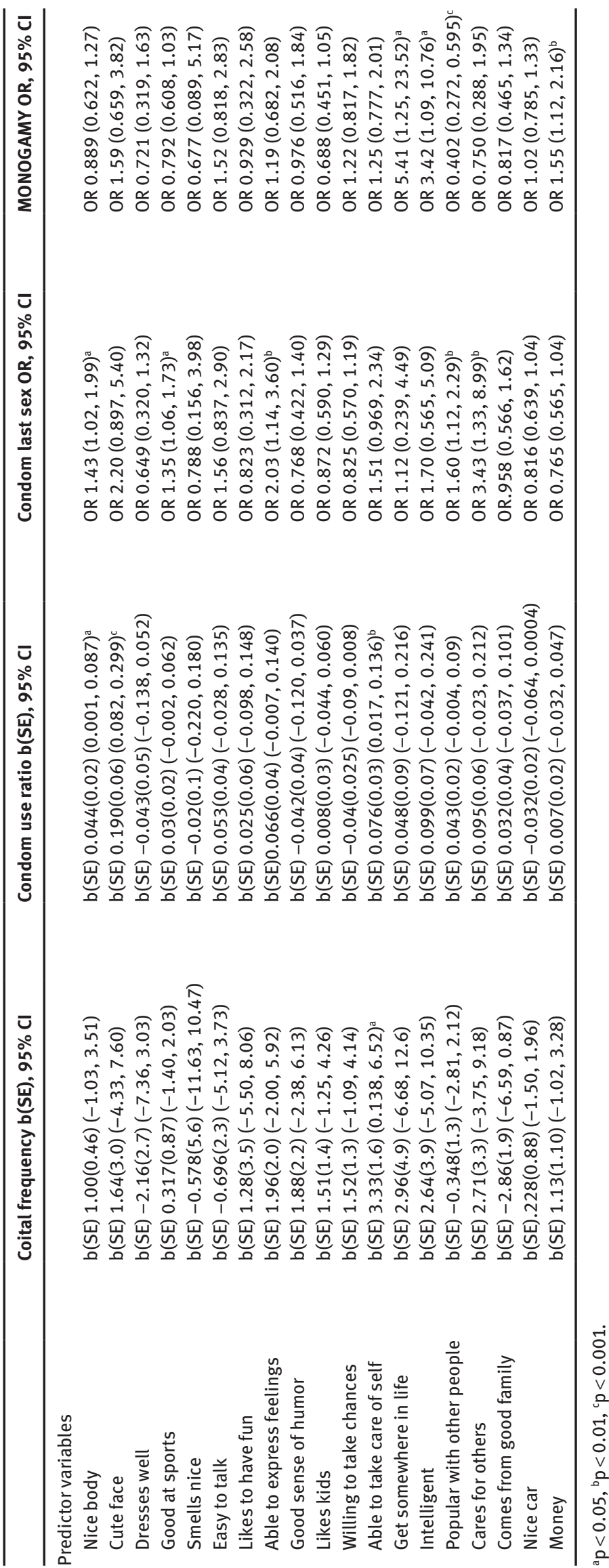


[OR 6.77, (1.51, 30.36, $\mathrm{p}<0.01)]$, being intelligent [OR 4.02, $(1.23,13.23, \mathrm{p}<0.05)]$ and having money [OR 2.41, (1.51, $3.84, \mathrm{p}<0.001)$ ] were more like the young man compared to the young woman (Table 2).

Current relationship monogamy was significantly less likely if being popular with other people [OR 0.501, (0.293, 0.856, $\mathrm{p}<0.01)$ ] was more like the male partner compared to the young woman. Liking kids was of borderline significance [OR 0.596, $(0.351,1.01, \mathrm{p}<0.056)]$.

\section{Condom use at last sex}

\section{Like Him v. Like Us}

Condom use at last sex was significantly more likely when having a nice body [OR 1.42, $(1.02,1.99, \mathrm{p}<0.05)$ ], being good at sports [OR 1.35, $(1.06,1.73, \mathrm{p}<0.05)]$, being able to express feeling [OR 2.03, $(1.14,3.60, \mathrm{p}<0.01)$ ], being popular with other people [OR 1.60, $(1.12,2.29$, $\mathrm{p}<0.01)$ ], and caring for others [OR 3.43, $(1.32,8.98$, $\mathrm{p}<0.01)$ ] was more like the young man compared to the dyad (Table 1).

\section{Like Him v. Like Me}

The use of a condom during most recent vaginal intercourse decreased when having a nice car [OR 0.686, $(0.488,0.964, \mathrm{p}<0.05)]$, dressing well [OR $0.413,(0.186$, $0.920, \mathrm{p}<0.05)$ ], and having money [OR 0.608, $(0.396$, $0.935, \mathrm{p}<0.05)$ ] described the young man compared to the young woman (Table 2).

\section{Coital frequency}

\section{Like Him v. Like Us}

Frequency of vaginal intercourse significantly increased when being able to take care of self [OR 3.33, $(0.138,6.52$, $\mathrm{p}<0.05)]$ described the male partner compared to the dyad (Table 1).

\section{Like Him v. Like Me}

There were no significant differences in coital frequency comparing the male partner to the young woman.

\section{Ratio of condom use during vaginal sex}

\section{Like Him v. Like Us}

The condom use ratio significantly increased when being able to take care of self [OR 0.076, $(0.017,0.136, \mathrm{p}<0.01)$ ], having a nice body [OR 0.044, $(0.001,0.09, \mathrm{p}<0.05)]$ and having a cute face [OR 0.190, $(0.082,0.30, \mathrm{p}<0.001)]$ were more like the young man compared to the dyad (Table 1 ).

\section{Like Him v. Like Me}

The ratio of condom use also increased when having a cute face $[\mathrm{OR} 0.194,(0.077,0.311, \mathrm{p}<0.001)]$ and being able to take care of self [OR 0.091, $(0.014,0.168, \mathrm{p}<0.05)$ ] were more like the male partner compared to the young woman (Table 2).

\section{Discussion}

Interpersonal characteristics appear to affect sexual behaviors and frequency within adolescent sexual relationships. Our study supports that sexual behaviors are not impervious to environment, and adolescents are balancing personal and ideal partner characteristics within relationships.

Current relationship monogamy increased when male partners were described by the young women as wanting to get somewhere in life, intelligent and having money. Such characteristics emphasize a cost-reward balance within relationships with factors like economics and education. Monogamy decreased when partners were described as popular with others suggesting a partner's role within social groups affects relationships and sexual behaviors (i.e. being unwilling to commit to one sexual partner due to high social standing). Perceiving her partner as more popular than she is, a young woman may be willing to compromise monogamy in order to maintain the relationship.

Male partners portrayed as having a nice body, popular and able to express feelings were more likely to use a condom at last sex within a couple, but condom use during last vaginal intercourse decreased when male partners had a nice car, dressed well and had money. Therefore, a young woman may compromise by not using a condom to keep a financially stable partner. These findings support previous work where women in adult sexual relationships valued financial stability in male partners and often relaxed partner standards in long-term relationships (14). 


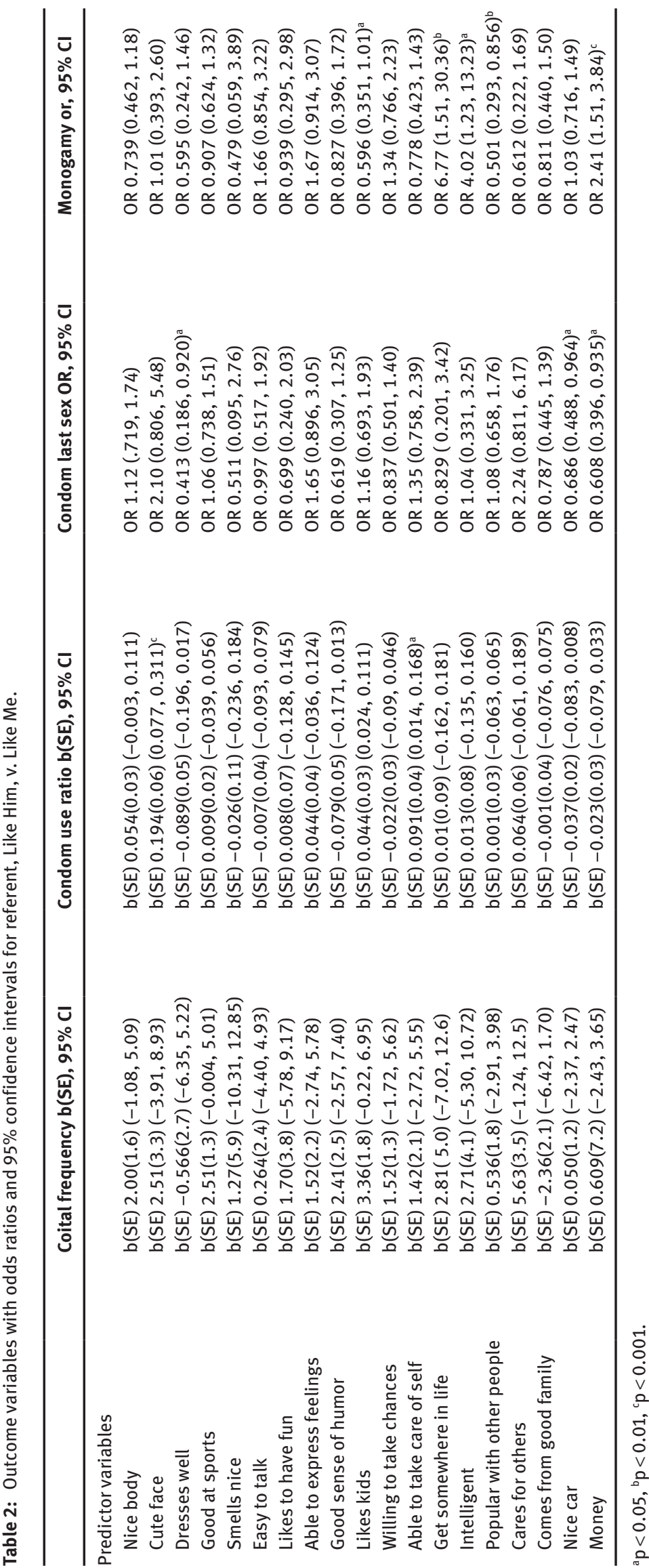


Coital frequency increased when partners were able to care for self, emphasizing the importance of social and financial stability. The condom use ratio during vaginal sex increased with a cute partner, a nice body and high self-care. In some studies, short- and long-term sexual pairings were influenced by the female's desire to have an attractive partner (15). Our findings support this premise while also suggesting other factors may affect condom use over time. Adult relationship studies also show women value social status and symbols of strength leading to compromises in sexual behaviors to maintain relationships (11). For young women, self-care is balanced with desires such as engaging in sexual intercourse and having a child, both of which affect decisions to use condoms in relationships.

Another factor to consider in adolescent relationships is availability of partners. Previous studies with teens have shown that as perceived availability of ideal partners increases, partner discordance on fidelity decreased (6). Therefore, if a young woman considers her partner options and does not see any preferred partners, she may be willing to compromise on ideal partner characteristics in order to have a partner.

Limitations of study design must be assessed in consideration of results. Study participants were primarily African-American young women receiving care in an urban setting. Although the data are not representative of adolescent women as a whole, they do explore the role of interpersonal characteristics in sexual partner relationships that are key to understanding adolescent sexual health in a global sense. Our study also is from the sole perspective of a young woman in a romantic partnership and her view of herself, her partner, and the partnership. Thus, the view of the male partners is not included in the data.

This study is important as it emphasizes the roles of both personal and partner characteristics in relationships as well as sexual behaviors and sexual risk factors like STI and pregnancy. Frequent discussions with adolescent women regarding personal and partner choice are essential in sexual health and should happen at multiple visits as sexual partners, behaviors and motivations for partner choice frequently change.

\section{Sources of support}

NIAID U01AI3194, NIAID T32AI07637, NICHD R01 HD044387-03. CDC through AAMC, \#U36/CCU319279/ MM-0467-03/3. The sources of support had no role in study design.
Acknowledgments: Authors of our manuscript would like to thank staff of the Young Women's Project for assisting in data collection during this project.

Conflicts of interest statement: Authors have no conflicts of interest that would interfere with this manuscript and its publication.

\section{References}

1. Kann L, Kinchen S, Shanklin SL, Flint KH, Kawkins J, et al. Youth risk behavior surveillance - United States, 2013. MMWR Surveill Summ 2014; 63(Suppl 4):1-68.

2. Hensel DJ, Fortenberry JD. A multidimensional model of sexual health and sexual and prevention behavior among adolescent women. J Adolesc Health 2013;52:219-27.

3. Andrinopoulos K, Kerrigan D, Ellen JM. Understanding sex partner selection from the perspective of inner-city black adolescents. Perspect Sex Reprod Health 2006;38:132-8.

4. Simon VA, Aikins JW, Prinstein MJ. Romantic partner selection and socialization during early adolescence. Child Dev 2008;79:1676-92.

5. Polk S, Ellen JM, Chung SE, Huettner S, Jennings JM. Discordance between adolescent real and ideal sex partners and association with STI risk behaviors. J Adolesc Health 2011;48:604-9.

6. Matson PA, Chung SE, Ellen JM. Perceived neighborhood partner availability, partner selection, and risk for sexually transmitted infections within a cohort of adolescent females. J Adolesc Health 2014; 55:122-7.

7. Seiffge-Krenke I, Burk WJ. Friends or lovers? Person-and variable-oriented perspectives on dyadic similarity in adolescent romantic relationships. J Soc Pers Relatsh 2013;30:711-33.

8. Fletcher GJO, Tither JM, O'Loughlin C, Friesen M, Overall N. Warm and homely or cold and beautiful? Sex differences in trading off traits in mate selection. Pers Soc Psychol Bull 2004;30:659-72.

9. Li NP, Kenrick DT. Sex similarities and differences in preferences for short-term mates: What, whether, and why. J Pers Soc Psychol 2006;90:468-89.

10. Eastwick PW, Finkel EJ. Sex differences in mate preferences revisited: Do people know what they initially desire in a romantic partner? J Pers Soc Psychol 2008;94:245.

11. Regan PC, Levin L, Sprecher S, Christopher FS, Gate R. Partner preferences: What characteristics do men and women desire in their short-term sexual and long-term romantic partners? J Psychol Human Sex 2000; 12:1-21.

12. Ha T, Overbeek G, Engels RCME. Effects of attractiveness and social status on dating desire in heterosexual adolescents: an experimental study. Arch Sex Behav 2010; 39:1063-71.

13. Fortenberry JD, Temkit M, Tu W, Graham CA, Katz BP, et al. Daily mood, partner support, sexual interest and sexual activity among adolescent women. Health Psychol 2005;24:252-7.

14. Stewart S, Stinnett H, Rosenfeld LB. Sex differences in desired characteristics of short-term and long-term relationship partners. J Soc Pers Relatsh 2000;17:843-53.

15. Bryan AD, Webster GD, Mahaffey AL. The big, the rich, and the powerful: Physical, financial, and social dimensions of dominance in mating and attraction. Pers Soc Psychol Bull 2011;37:365-82. 